\title{
Do valor da história à história dos valores*
}

\author{
Bertrand Binoche ${ }^{* *}$
}

\begin{abstract}
Resumo: A questão colocada por Nietzsche em 1874 é explicitamente a do valor da história e só pode ser colocada porque reporta a história a uma instância exterior, a vida, qualificada então como não histórica. Em 1878, Nietzsche inverte sua interrogação e preconiza uma "filosofia histórica" que identifica vida e história, abrindo assim a possibilidade de uma história dos valores. O problema consiste agora em saber como concretizar esta última. Nietzsche recorre então ao esquema utilitarista, com o qual começa uma longa discussão, como testemunha muito bem, em 1882, $A$ gaia ciência. Em 1887, o próprio conceito de "genealogia" é empregado para significar uma nova historicidade, cuja possibilidade mesma depende da liquidação prévia desse modelo, de modo que a crítica a Paul Rée deve ser compreendida também como uma autocrítica.
\end{abstract}

Palavras-chave: história - valor - genealogia - utilitarismo

Sem dúvida, Deleuze vai direto ao ponto declarando no início de seu célebre comentário: "O projeto mais geral de Nietzsche consiste nisto: introduzir em filosofia os conceitos de sentido e de valor". Deixemos aqui o "sentido"; permanece verdadeiro que com Nietzsche o conceito de "valor" adquire uma significação e um estatuto inéditos. Uma significação porque o valor não é mais simplesmente o valor moral de que falavam os clássicos, que "não dependia do passar dos anos" e que se devia compreender em

* Tradução de Eder Corbanezi.

** Professor da Université Paris-I/Panthéon-Sorbonne, França. Endereço eletrônico: bertrand. binoche@univ-paris1.fr. Agradeço a Arnaud Sorosina, que me releu com uma preciosa atenção. 1 DELEUZE, G. Nietzsche et la philosophie. Paris: PUF, 1962, p.1. 
Binoche, B.

referência à estima pública; tampouco é, evidentemente, ou, em todo caso, ultrapassa amplamente o valor econômico, que, como Marx se esforçava para mostrar, era preciso subtrair à ideologia burguesa. Com Nietzsche, é antes o valor que se substitui à ideologia; é ele que se deve interpretar e é ele que conduz, por uma virada ao mesmo tempo bem conhecida mas ainda desconcertante, a pôr em questão o próprio conceito de verdade, que a ideologia, ao contrário, deixava intacto. Ao mesmo tempo, o valor se torna o objeto central da filosofia: o que é um valor; como ele não existe sem uma vontade de potência que se esforça para impô-lo - de modo que é totalmente inepto falar dos "valores" como se subsistissem num éter platônico e pudessem ser escolhidos, ou não, livremente; como o valor aparece, é objeto de múltiplas apropriações ao sabor dos conflitos em que se encontra envolvido, e desaparece; como ele próprio tem um valor; quais valores é preciso promover e como podem ser promovidos: eis o que define propriamente o espaço de investigação que Nietzsche cria por um gesto cujo caráter criador reivindica orgulhosamente, mas de maneira legítima.

Apropriando-se assim do conceito de valor, Nietzsche se coloca então em um novo terreno, a partir do qual pode tomar posição sobre uma questão que talvez seja $a$ grande questão com que se confrontam os filósofos do século: a história. A questão não é, aliás, somente filosófica, e muito foi escrito sobre a institucionalização disciplinar desta. Avancemos um passo: o próprio afastamento entre a história dos historiadores e a dos filósofos, entre a reconstituição do que aconteceu tal como aconteceu e a inscrição do que aconteceu numa teleologia seletiva que fornece a verdade, esse afastamento é certamente decisivo, é o lugar de um litígio recorrente. Mas Nietzsche se encontra aí confrontado inicialmente a partir de outro divórcio: aquele que opõe a história filológica a uma filosofia não histórica - a de Schopenhauer ${ }^{2}$. O nascimento da tragédia já se

2 SCHOPENHAUER, A. Le monde comme volonté et représentation, suplementos, 38: “(...) ela

36 I Cad. Nietzsche, São Paulo, n. 34 - vol. I, p. 35-62, 2014. 
constrói como uma tentativa acrobática para absorver tal cisão, e é possível pensar que no fundo se encontra aí uma preocupação que irriga em profundidade o percurso nietzschiano e que se poderia formular assim: como ser filósofo $e$ historiador sem ser um filósofo $d a$ história? A resposta final será: sendo "genealogista".

É essa tese que o presente artigo pretende justificar estabelecendo a seguinte escansão: o problema da história se põe de início a Nietzsche como aquele de seu valor, este podendo determinar-se, por hipótese, apenas em referência a um estalão não histórico - a vida. Mas, em 1878, o projeto de uma "filosofia histórica", cuja materialização privilegiada é uma história dos sentimentos morais, o conduz a inverter a questão e a conceber uma história dos valores. A dificuldade consiste então em saber como de fato escrever tal história sem reintroduzir a teleologia recusada inicialmente, e é para tanto que Nietzsche recorre ao motivo utilitário. Tem início uma longa discussão com o utilitarismo, e a genealogia stricto sensu só poderá instaurar-se, em 1887, sobre sua liquidação retroativa. Em suma, em vez de perguntar-se que valor tem a história, é preciso perguntar-se antes como a história permite pensar o problema dos valores; ora, ela o permite com eficácia somente ao emancipar-se do utilitarismo (mas qual ao certo?), afirmando que a própria utilidade é um valor que deve tudo a formas de vida muito pouco entusiasmantes.

\section{A história}

É, sem dúvida, lícito abordar a segunda Extemporânea como uma justificação retrospectiva de $O$ nascimento da tragédia. É primeiramente uma resposta aos filólogos de profissão que julgaram

[a história] pretende nos contar a cada vez outra coisa, enquanto, do começo ao fim, é a repetição do mesmo drama, com outras personagens e sob trajes diferentes" (trad. A. Burdeau. Paris: PUF, 1978, p.1184). 
Binoche, B.

insuficientemente histórica a obra de 1872, consistindo ela em minorar a "história" ao referi-la a uma instância superior, a "vida". Eis por que não se deve negligenciar o título de 1874: Vom Nutzen und Nachteil der Historie für das Leben. A introdução logo o parafraseia anunciando uma "Betrachtung über den Wert und den Unwert der Historie". É certo que Schopenhauer já havia colocado a questão do valor [Wert] da história no capítulo 38 dos suplementos do $\mathrm{Mundo}^{3}$; mas era preciso então conferir ao termo seu sentido ordinário e perguntar-se qual interesse tinha o estudo da história, com que finalidade se consagrar a ela, como, por exemplo, já fazia Schiller em sua célebre aula inaugural de $1789^{4}$, mesmo se fosse para responder de maneira totalmente diversa. Para Nietzsche, o termo "valor" adquire um sentido novo e importante, devendo ser entendido em oposição, por um lado, à verdade, e, por outro, ao sentido: não se trata de determinar quais são as condições requeridas para se ter um discurso verdadeiro sobre os fatos passados; tampouco se trata de envolver estes num curso racional que conduziria um sujeito à consciência de si próprio; trata-se de determinar se a história favorece a vida, isto é, ao mesmo tempo qual tipo de história favorece a vida e qual tipo de vida é favorecido pelo estudo da história. À questão então crucial de saber o que pode significar este vocábulo enigmático, a “vida", o $§ 1$ responde que ela consiste numa "força que permite a alguém desenvolver-se de maneira original e independente, transformar e assimilar coisas passadas ou estrangeiras, curar suas feridas, reparar suas perdas, reconstituir por si próprio as formas quebradas"5. Ao fim do mesmo parágrafo, Nietzsche precisa explicitamente - e como poderia fazer de outro modo, se pretende servir-se dela para avaliar a história - que a vida é não histórica: “A história, na medida em que está a serviço da

3 Schopenhauer, op. cit., p.1185.

4 Cujo título era significativo: Was heisst und zu welchem Ende studiert man Universalgeschichte? Nietzsche menciona explicitamente esse texto em HL/Co. Ext. II 6, KSA 1.291.

5 HL/Co. Ext. II 1, KSA 1.251.

38 I Cad. Nietzsche, São Paulo, n. 34 - vol. I, p. 35-62, 2014. 
vida, está a serviço de uma potência a-histórica [unhistorisch]"6. Se a definição mesma da vida a afasta da vontade schopenhaueriana e sua definição como vontade de potência a afastará ainda mais ${ }^{7}$-, essa última característica, ao contrário, aproxima-a dela.

Opondo-se à verdade e ao sentido do ponto de vista do valor, certamente Nietzsche não justifica apenas o uso instrumental que fez da filologia em 1872; ele encontra a ocasião para fazer um balanço que retira a razão de seus rivais ao mostrar que a história positiva e a filosofia da história são igualmente patogênicas.

\section{I.1. A vida contra a história}

Quanto à história acadêmica, ela se revela perigosa na medida em que se emancipa da vida em nome da verdade. A ameaça, que já começou a produzir amplamente seus efeitos desastrosos, deve-se ao fato de que semelhante preocupação com a verdade afasta toda discriminação vital: a partir do momento em que se determina que a história se torne por vocação uma ciência e se exige prioritariamente que seja verdadeira, deve-se efetuar a abstração radical e mutiladora de sua relação com a vida: "Certamente um tal astro, um astro luminoso e soberbo, se interpôs [entre a história e a vida], a constelação efetivamente se alterou - pela ciência, pela exigência de que a história seja ciência"8. Ora, isso traz duas consequências distintas, mas indissociáveis. A primeira é que uma tal prática da história é inevitavelmente paralisante: nada permitindo mais selecionar entre os fatos verdadeiros aqueles que importam reter, o passado se torna o apeiron sob o qual o presente se encontra imerso - "(...) tudo o que era uma vez precipita-se sobre o homem. Até onde houve um vir-a-ser, até lá se deslocaram, para trás, ao

6 HL/Co. Ext. II 1, KSA 1.257, trad. Rubens Rodrigues Torres Filho.

7 Ver o Nachlass/FP 1886-1887, 7[9], KSA 12.286. E MÜLLER-LAUTER, W. Nietzsche.

Physiologie de la volonté de puissance. Trad. J. Champeaux. Paris: Allia, 1998, p.116-117.

8 HL/Co. Ext. II 4, KSA 1.271, trad. Rubens Rodrigues Torres Filho. 
Binoche, B.

infinito, todas as perspectivas" $"$. E os mortos, longe de se enterrarem os mortos, sufocam sem vergonha os vivos. A segunda consequência é o nivelamento: todo fato verdadeiro, enquanto verdadeiro, vale tanto quanto um outro, não havendo assim nenhuma razão para interessar-se antes por um que por outro, mesmo quando se trata de filosofia: "Admitindo que um deles se ocupe com Demócrito, está sempre em meus lábios a pergunta: mas por que justo Demócrito? Por que não Heráclito? Ou Filon? Ou Bacon? Ou Descartes? - e assim por diante, à vontade" ${ }^{10}$. É essa negação da hierarquia que mais tarde conduzirá Nietzsche a associar a erudição à plebeidade democrática $^{11}$ e a fazer dela uma expressão, entre outras, do niilismo $^{12}$ : a história verdadeira é a história que acredita recusar todo juízo de valor, sem ver que acredita na verdade.

É bastante notável que a esse passado rebentando na humanidade moderna Nietzsche oponha, como parapeito, a arte (a começar pela de Wagner), a religião (a dos mitos, gregos ou germânicos, que transfiguram o passado em função do presente) e, enfim, a filosofia (a de Schopenhauer em primeiro plano) ${ }^{13}$. Elas aparecem então como potências de eternidade, e é à luz de tais textos que se deve ler a notável carta a Malwida von Meysenbug de 14 de janeiro de 1880: "No que concerne aos tormentos e às outras privações, pode-se comparar a minha existência nos últimos anos com a de qualquer asceta de qualquer época; todavia, retirei desses anos muitas coisas para purificar e polir a alma - e, para isso, não preciso mais nem da religião, nem da arte" ${ }^{\text {"14 }}$. É que, com efeito, não se tratará mais de desviar-se do vir a ser, muito ao contrário, mas de elaborar uma filosofia que permita nele permanecer.

9 HL/Co. Ext. II 4, KSA 1.272, trad. Rubens Rodrigues Torres Filho.

10 HL/Co. Ext. II 5, KSA 1.283, trad. Rubens Rodrigues Torres Filho. Hoje, acrescentar-se-ia naturalmente: "Ou Nietzsche?"...

11 JGB/BM 224, KSA 5.157-160.

12 GM/GM III, 26, KSA 5.405-408.

13 HL/Co. Ext. II 5 e 10, p.123-124 e 166 ed. francesa.

14 Os grifos são meus. Citado por JANZ, C.P. Nietzsche. Biographie. Trad. fr. P. Rusch. Paris: Gallimard, 1984, t.II, p.300.

40 I Cad. Nietzsche, São Paulo, n. 34 - vol. I, p. 35-62, 2014. 
Em todo caso, a grande tese de 1872 é que se deve reconduzir a história ao seu caráter naturalmente auxiliar; ela deve servir à vida, isto é, ao presente, em vez de voltar-se contra ele e de asfixiá-lo: "É apenas a partir da mais elevada força do presente que vós possuís o direito de interpretar o passado (...)" "15. Mas o que é ao certo "a mais elevada força do presente"? Afinal de contas, Schiller também dizia, em 1789, que o historiador não se podia preocupar com todos os acontecimentos dos quais conservamos traços e que lhe era preciso reter exclusivamente "aqueles que tiveram sobre a forma atual do mundo e o estado da geração viva hoje uma influência essencial, irrecusável e fácil de seguir" ${ }^{16}$. Já não era então dizer que a história deve ser explorada tendo-se em vista o presente?

\section{I.2. A vida contra a filosofia da história}

Evidentemente, não: a mais elevada força do presente não é o presente como télos do curso universal das coisas, mas um presente que se insurge contra o presente da opinião pública (da massa) e que ordena uma outra redefinição do passado. É aqui que encontramos a segunda linha de frente em que combate Nietzsche, aquela das "filosofias da história", as quais devem significar aqui as grandes teleologias que conferem retrospectivamente um sentido à história universal. São elas que Nietzsche ataca explicitamente nos $\S \S 8$ e 9 sob os nomes de Hegel e Hartmann (HL/Co. Ext. II 8 e 9, KSA 1.302-324). Que Nietzsche se distancie da Geschichtsphilosophie não pode surpreender, se lembrado o vigor com que Burckhardt havia rejeitado tal conceito no início das aulas sobre a história universal de 1870-1871, vendo nele "um monstro híbrido, uma contradictio in adjecto, pois a história que coordena é

15 HL/Co. Ext. II 6, KSA 1.293-294.

16 "Was heisst und zu welchem Ende studiert man Universalgeschichte?". In: Werke. Weimar: H. Böhlhaus, 1970, t.XVII, p.371 : "Aus der ganzen Summe dieser Begebenheiten hebt der Universalhistoriker diejenigen heraus, welche auf die heutige Gestalt der Welt und den Zustand der jetzt lebenden Generation einen wesentlichen, unwidersprechlichen und leicht zu verfolgenden Einfluss gehabt haben". 
Binoche, B.

a negação da filosofia, enquanto a filosofia que subordina é a negação da história"17. Certamente Nietzsche não se limitará a essa disjunção, mas sempre se recusará a reivindicar uma "filosofia da história", como testemunha, sem equívoco, o uso ulterior dos termos "filosofia histórica" e, depois, "genealogia"18. E as duas principais censuras que ele dirige aqui à herança hegeliana, designada como tal, podem ser tidas por definitivas.

A primeira delas, que terá uma posteridade considerável na grande querela alemã da "secularização", consiste em destruir a pretensão hegeliana de encontrar na história a forma acabada da teodiceia, uma "justificação de Deus"19. Nietzsche replica que, sendo de fato assim, toda tentativa de ordenar a história a um sentido equivale, em consequência, a produzir uma "teologia embuçada" $" 20$ ou ainda o que a quarta Extemporânea denuncia como uma "teodiceia cristã embuçada" ${ }^{21}$. É exato que a filosofia da história justifica Deus, mas é precisamente por essa razão que é preciso colocá-la porta afora.

No $\S 8$, Nietzsche descreve assim a reciclagem da teologia na filosofia da história. A crença no Juízo Final impunha ao cristão a lembrança de que era mortal - memento mori - e lhe ensinava a inconsistência do que podia suceder neste mundo; ora, essa desvaloração se encontra reconduzida pela hipertrofia moderna do sentido histórico, que, recusando a velha escatologia, perpetua tal

17 Considérations sur l'histoire universelle. Trad. fr. S. Stelling-Michaud. Paris: Payot, 1965, p.34. Esse argumento é a paráfrase manifesta daquele que empregava Schopenhauer no início do capítulo 38 dos suplementos (trad. cit., p.1179), o qual, por sua vez, lembrava-se evidentemente de Aristóteles.

18 Por isso, intitular um livro Nietzsche's Philosophy of History, como fez recentemente A. K. JENSEN (Cambridge U.P., 2013), constitui um contrassenso terminológico - isso dito sem prejulgar o conteúdo de tal obra, antes de cuja aparição este artigo foi redigido.

19 HEGEL, G.W.F. La philosophie de l'histoire. Trad. M. Bienenstock et al. Paris: Librairie générale française, 2009, p.61. Sabe-se que é Droysen que fala nominalmente de "Theodizee der Geschichte" no $§ 48$ do Grundriß der Historik, publicado pela primeira vez em 1858.

20 HL/Co. Ext. II 8, KSA 1.305, trad. Rubens Rodrigues Torres Filho.

21 WB/Co. Ext. IV 3, KSA 1.445.

42 I Cad. Nietzsche, São Paulo, n. 34 - vol. I, p. 35-62, 2014. 
desvaloração sob a forma de um ceticismo generalizado: "A consideração amarga e profundamente séria sobre o desvalor de todo o acontecido, sobre o estar-maduro-para-o-julgamento do mundo, liquefez-se na consciência cética de que, em todo caso, é bom saber todo o acontecido, porque é tarde demais para fazer algo de melhor"22. A filosofia da história por excelência, em que Hegel figura como o nome, aparece então como a inversão dessa desvaloração numa superestimação também aberrante: "Imaginemos, porém, que tais descendentes antiquários troquem de repente sua dolorosa e irônica modéstia por uma atitude perfeitamente impudente; imaginemos que eles se ponham a proclamar com uma voz estridente que a espécie atingiu seu apogeu, pois é somente agora que ela se conhece a si mesma" ${ }^{23}$. A filosofia da história é a história dos eruditos às avessas: de uma secularização a outra! O primeiro vício dessa filosofia moderna é então a ingenuidade com que reconduz a piedade tradicional, acreditando livrar-se dela: "Como, as religiões estariam à morte? Vede simplesmente a religião da potência histórica"24. Como dizia Marx de Bauer, é possível "evadir-se à teologia permanecendo teólogo" 25 . Mas se sabe que o argumento adquirirá em Nietzsche uma envergadura considerável, a ponto de tornar-se, por fim, o próprio programa de seu empreendimento: como não secularizar o cristianismo e livrar-se das sombras de Deus? Programa, a bem dizer, infinito, que irrigará uma grande parte do século seguinte.

Por ora, é preciso dizer que tal ingenuidade leva consigo três outras hipotecas. Em primeiro lugar, a filosofia da história é extravagante por sua pretensão: como é possível seriamente se crer no ápice da história universal? Em seguida, ela é inconsequente:

22 HL/Co. Ext. II 8, KSA 1.305, trad. Rubens Rodrigues Torres Filho.

23 HL/Co. Ext. II 8, KSA 1.307-308.

24 HL/Co. Ext. II 8, KSA 1.309, trad. Rubens Rodrigues Torres Filho.

25 MARX, K. L'idéologie allemande. In: Euvres. Trad. M. Rubel. Tomo III. Paris: Gallimard, 1982, p.1199. 
Binoche, B.

consciente do ridículo de sua tese, Hegel não ousa declarar o que, contudo, dela deduz-se necessariamente: "Aliás, ele teria mesmo de dizer que todas as coisas que viriam depois dele só devem ser avaliadas, propriamente, como a coda musical de um rondó da história universal ou, ainda mais propriamente, como supérfluas. Isso ele não disse (..." ${ }^{926}$. Enfim, e trata-se do pior, ela é servil na medida em que transforma o homem moderno num "adorador do processo" ", num "idólatra do real" que curva a espinha diante dos fatos e se inclina diante de todo sucesso, já que a História é seu verdadeiro sujeito. Este último argumento é digno de interesse, por um lado porque volta contra Hegel a crítica que este havia endereçado aos partidários da Escola histórica do direito ${ }^{28}$; por outro, porque tal resignação generalizada a tudo o que acontece se assemelha muito ao amor fati defendido ulteriormente, de sorte que será preciso distinguir dois modos de sim, o que zurra um asno bem leibniziano e o que preconiza Zaratustra ${ }^{29}$ - assim como será preciso distinguir dois modos de não, o do ressentimento e o do martelo ${ }^{30}$.

26 HL/Co. Ext. II 8, KSA 1.308-309, trad. modificada Rubens Rodrigues Torres Filho. Nietzsche se mostra assim um leitor mais prudente do que Kojève...

27 Segundo a poderosa fórmula de HL/Co. Ext. II 1, KSA 1.256.

28 HEGEL, Principes de la philosophie du droit, § 3.

29 ZA/ZA III, Do espírito de gravidade, KSA 4.241, trad. Paulo César de Souza. A menção ao "melhor dos mundos" reenvia claramente à teodiceia, à de Leibniz mas também à de Hegel. Mas o problema já se colocava em 1873, no $\$ 7$ de A filosofia na época trágica dos gregos (KSA 1.830-833), quando Nietzsche opunha Heráclito (o mundo como jogo) a Leibniz (o melhor dos mundos possíveis): a "justificação do vir-a-ser" (PHG/FT 5, KSA 1.822, trad. Rubens Rodrigues Torres Filho) nunca foi a justificação de Deus. Ver também MA I/HH I 28, KSA 2.49 (trad. Paulo César de Souza): "Deixando de lado a teologia e o combate que se faz a ela, fica evidente que o mundo não é nem bom nem mau, e tampouco o melhor ou o pior (...)". Ou ainda o Nachlass/FP 1888, 16[32], KSA 13.492-493, que distingue o consentimento ao que é desejável da resignação ao necessário.

30 Não há espaço aqui para deter-se na violenta crítica a Hartmann operada no § 9; ela foi estudada por J. Salaquarda no terceiro de seus "Studien zur zweiten unzeitgemäßen Betrachtungen". In: Nietzsche-Studien, n.13, 1984, p.30-45. O essencial me parece ser que Hartmann aparece como um avatar burlesco do hegelianismo e que a própria virulência do ataque deve sem dúvida ser compreendida pela necessidade de demarcar-se de uma tentativa destinada a reconciliar Hegel e Schopenhauer que havia obtido em 1869 com Filosofia do inconsciente um sucesso considerável: do ponto de vista de Nietzsche, não há razão para efetuar qualquer reconciliação, mas sim para subordinar a história à vontade redefinida como vida. 
A segunda grande reprimenda que Nietzsche dirige à filosofia da história diz respeito ao fato de ser ela, por essência, uma história democrática, de perder, portanto, os únicos indivíduos dignos de interesse, a saber, os grandes homens que, longe de representarem o espírito dos povos, constituem como que uma "cumeada"31, heroica porque intempestiva, da humanidade. Com efeito ${ }^{32}$, a filosofia da história pretende formular leis da história ${ }^{33}$; tais leis, porém, são concebíveis apenas se o historiador trabalha sobre massas, que fazem aparecer regularidades estatísticas ${ }^{34}$ - aqui é preciso considerar "massa" em duplo sentido, como grande número matemático e como populacho; portanto, o filósofo pode enunciar as leis da história somente porque escreve a história das massas, isto é, a história que tem por objeto as massas porque é escrita do ponto de vista das massas $^{35}$. Pretendendo-se, ao contrário, trabalhar sobre as grandes individualidades inatuais da história monumental, nenhuma regularidade será mais então observável. A obra que manifesta da maneira mais notável a conexão entre uma história que formula leis e uma história do povo é, em 1867-1869, Guerra e Paz, em que Tolstoi não cessa de negar a importância de Napoleão, opondo-lhe o povo russo: "Para procurar as leis da história, devemos mudar inteiramente o objeto de nosso exame, deixar de lado reis, ministros e generais para escrutar os elementos homogêneos, infinitesi-

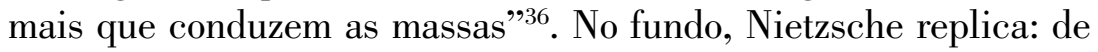
fato, e é precisamente por isso que não devemos procurar tais leis!

31 HL/Co. Ext. II 2, KSA 1.259.

32 HL/Co. Ext. II 9, p.157 ed. francesa.

33 Cuja possibilidade Burckhardt já havia recusado: op. cit., p.243.

34 Seria preciso reler aqui a primeira página de Ideia de uma história universal de um ponto de vista cosmopolita de Kant.

35 Cf. TOCQUEVILLE. De la démocratie en Amérique, vol.II, part.I, cap.20.

36 TOLSTOI. Guerre et paix, liv.III, part.III, cap.1. Trad. fr. H. Mongault. Paris: Gallimard, 1952, p.1070-1072. Tolstoi foi um grande leitor (crítico) de Buckle, cuja History of Civilization in England Nietzsche descobriu em maio de 1887 (ver JANZ, C.P., op. cit., t.III, p.256). O primeiro capítulo desta última obra é uma apologia das estatísticas, na medida em que elas demonstram que as ações dos indivíduos se sujeitam ao "estado geral da sociedade". 
Binoche, B.

Em 1874, as vantagens da história para a vida são menos notáveis do que suas ameaças, e o essencial é que ela $n \tilde{a} o$ é a vida a serviço da qual deve permanecer enfeudada ${ }^{37}$.

\section{A filosofia histórica}

\section{II.1. Filosofia histórica versus filosofia metafísica}

Em 1878, basta abrir Humano, demasiado humano em sua primeira página para constatar que o problema se coloca de maneira totalmente diversa: em vez de opor a história à filosofia (assim como à arte e à religião), Nietzsche opõe a "filosofia histórica" à "filosofia metafísica". Ele evita cuidadosamente dizer die Geschichtsphilosophie ou die Philosophie der Geschichte e emprega die historische Philosophie (MA I/HH I 1, KSA 2.23) ou das historische Philosophieren (MA I/HH I 2, KSA 2.25): o que equivale a dizer que não se trata de refletir enquanto filósofo sobre a história, ordenando-a conforme um sentido, mas de filosofar historicamente, isto é, de mostrar a realidade histórica do que parecia eterno. $\mathrm{O}$ filosofar histórico é um fazer, e não uma reflexão.

Mas como se define a filosofia metafísica? Ela consiste aqui ${ }^{38}$ em colocar aquilo de que se fala - o Justo, o Belo ou o que quer que seja - como se tivesse sempre existido: assim ocorre com as ideias platônicas, e sabe-se que Nietzsche evocará mais tarde como “o pior, mais persistente e perigoso dos erros (...) a invenção platônica do puro espírito e do bem em si" ${ }^{\text {"39. }}$. Esquiva-se assim da dificuldade, que consiste precisamente em saber, ao contrário, como isso adveio, de onde provém. Mas seria um engano acreditar que

37 Por falta de espaço, deixo de lado aqui a delicada questão de saber em que sentido precisamente o heraclitianismo moderno pode ser dito "verdadeiro" (HL/Co. Ext. II, p.96, 156-157 e 166 ed. francesa).

38 Cf. Nachlass/FP 1883, 8[25], KSA 10.342-343.

39 No prefácio de JGB/BM, KSA 5.12, trad. Paulo César de Souza.

46 I Cad. Nietzsche, São Paulo, n. 34 - vol. I, p. 35-62, 2014. 
a filosofia $d a$ história rompe com esse dogmatismo: na verdade, ela só o prolonga, já que coloca o fim no começo, de modo que nada pode acontecer de novo. É o que mais à frente Nietzsche denomina "a divinização do vir a ser", precisando que se trata de "uma perspectiva metafísica" 40 , o que se deve entender em sentido próprio. Filosofar historicamente é, ao contrário, pensar o vir a ser sem divinizá-lo, sem procurar nele a revelação imanente de Deus - imanente ou não, aliás, o que importa? Mas é, todavia, pensá-lo, e não se contentar, como Schopenhauer, que é evocado imediatamente, em "negar a evolução" e "dar vazão a seu escárnio"41. É notável observar como Nietzsche reencontra aqui o problema tal como Hartmann o colocava, em 1876, quando declarava que "a visão do mundo a-histórica" de Schopenhauer devia "ceder lugar a uma visão do mundo histórica" ${ }^{\text {"42 }}$. Nietzsche não diz outra coisa, salvo que a historicidade de que se trata de lançar mão não tem mais nada a ver com "a capacidade de desenvolvimento da Ideia", sob pena de negar o vir a ser no momento mesmo em que se lhe pretende dar lugar para melhor neutralizá-lo. Certamente não se trata mais de desviar-se dele, mas de saber manter-se nele para restituir a toda coisa a realidade fluente que impede precisamente de falar dela como uma coisa - não é esse, no fundo, o problema de Nietzsche?

O problema consiste então em saber o que pode significar em ato "filosofar historicamente". Retornando-se ao $§ 1$ (MA I/HH I 1, KSA 2.23, trad. Paulo César de Souza), pode-se discernir três pontos de referência, dos quais somente os dois primeiros são explícitos. Há em primeiro lugar a herança pré-socrática, com a qual se trata de reatar por sobre a época metafísica e que se caracteriza pelo fato de que então se perguntava "como pode algo se originar

40 MA I/HH I 238, KSA 2.200, trad. Paulo César de Souza: "Die Vergottung des Werdens ist ein metaphysischer Ausblick".

41 MA I/HH I 238, KSA 2.200, trad. modificada Paulo César de Souza.

42 HARTMANN, E. von. Le panthélisme de Schopenhauer. Trad. V. Stanek. In: Les Etudes Philosophiques, n.3, 2012, 419. 
Binoche, B.

do seu oposto": em vez de encerrar-se em antinomias, via-se toda realidade engendrar sua negação. Assim, por exemplo, Heráclito podia escrever: "a morte do fogo é nascimento do ar; a morte do ar, nascimento da água" (B 76), sem sentir a necessidade de reportar semelhante processo a um substrato não engendrado, o que equivalia a neutralizá-lo metafisicamente ${ }^{43}$. A essa longínqua herança acrescenta-se um modelo químico, totalmente moderno, que provavelmente deve muito a Paul Rée ${ }^{44}$ e atesta uma reavaliação positiva das ciências da natureza. Aqui, ele cauciona um pensamento da transformação como "sublimação" [Sublimirung] ou "volatilização" [verflüchtigen], induzindo a ideia de que o contrário observável à chegada é a forma vaporosa, aceitável e mesmo admirável do contrário inicial, que em realidade, porém, não desapareceu, mas subsiste assim mascarado no que ele se tornou. Todos os exemplos apresentados por Nietzsche no início do parágrafo têm em comum, aliás, o fato de que mencionam sempre como o presumido "positivo" nasce do presumido "negativo": "o racional do irracional, o sensível do morto, o lógico do ilógico, a contemplação desinteressada do desejo cobiçoso, a vida para o próximo do egoísmo, a verdade dos erros". Trata-se então de empregar "a observação mais refinada" para reencontrar o elemento originário, que é sempre o vil, o desprezado, em sua aparente negação, que não é dialética, uma vez que ela só faz reproduzi-lo dissimuladamente e assim conservá-lo, tornando-o irreconhecível, sem, de modo algum, “ultrapassá-lo”. Nesse ponto se adivinha a terceira referência, que sem dúvida Nietzsche também deve a Rée ${ }^{45}$ e que se une à precedente, a dos moralistas franceses, em particular La Rochefoucauld, que louvará, aliás, o § 36 (MA I/ HH I 36, KSA 2.59) e que dizia do amor-próprio: “(...) suas flexibilidades não se podem representar, suas transformações ultrapassam

43 ARISTÓTELES. Métaphysique, livro lambda, 1069 b 8-1070 a 30.

44 Ver D'IORIO, Paolo. Le voyage de Nietzsche à Sorrente. Paris: CNRS Editions, 2012, p.118-119 e 123-124, nota 16.

45 Ver JANZ, C. P., op. cit., t.II, p.204.

48 I Cad. Nietzsche, São Paulo, n. 34 - vol. I, p. 35-62, 2014. 
as das metamorfoses e seus refinamentos, os da química", antes de acrescentar: "ele é todos os contrários"46. Sem dúvida alguma, Nietzsche tomará distância de uma crítica que lhe parecerá insuficiente na medida em que continua a prejulgar a objetividade do bem e do $\mathrm{mal}^{47}$; mas ele jamais abandonará a ideia de que toda antinomia deve ser reinterpretada como a derivação de um contrário a partir de outro, do "positivo" a partir do "negativo"

O que se encontra igualmente estabelecido em 78 é o objeto dessa nova forma de história filosófica: a segunda parte de Humano, demasiado humano intitula-se "Para a história dos sentimentos morais [Zur Geschichte der moralischen Empfindungen]" (MA I/HH I, KSA 2.57-106, trad. Rubens Rodrigues Torres Filho). O simples fato de que os sentimentos morais tenham uma história é evidentemente notável, e é facilmente possível convencer-se disso reportando-se à célebre obra de Smith, A Teoria dos sentimentos morais (1759), que presumia justamente que estes não tinham história - história, se havia, dizia respeito somente aos sistemas de filosofia moral que a sétima parte estudava, e não aos próprios sentimentos. Quando Nietzsche disser, em 1881, que a história dos conceitos morais não é a dos sentimentos morais, isso significará, ao contrário, não que a história dos sistemas deva ser apreciada segundo a natureza verdadeira e imutável dos sentimentos, mas que a história dos sistemas esconde uma outra, bem mais interessante, a dos sentimentos que os julgamentos morais transformam ${ }^{49}$. Desde o $§ 2$ de Humano, demasiado humano (KSA 2.24-25), a "filosofia histórica" encontra

46 É a primeira das "máximas suprimidas": ver LAFOND, Jean (ed.). Moralistes du XVIIe siècle. Paris: Robert Laffont, 1992, p.179-180.

47 M/A 103, KSA 3.91-92.

48 JGB/BM 2, KSA 5.16-17. Por isso o termo Sublimirung reparecerá no coração da Genealogia (GM/GM II, 7, KSA 5.303), quando se tratar de descrever como se transformou a fruição da crueldade, o que Nietzsche chama ainda em outro lugar sua "espiritualização [Vergeistigung]" (JGB/BM 229, KSA 5.166) e o que, por fim, não é outra coisa senão o próprio processo de civilização tal qual o conhecemos. Ver também GD/CI, A “razão" na filosofia 4, KSA 6.76.

49 M/A 34 e 38, KSA 3.43 e 45-46. 
Binoche, B.

seu ponto de aplicação no próprio homem, que não foi sempre um homem, e o $\$ 32$ afirmará que não podemos viver sem "avaliar [abschätzen]" (MA I/HH I 32, KSA 2.52, trad. Paulo César de Souza): de fato, a questão que retorna então sem cessar no decorrer da obra é a do valor - o valor do sofrimento, da arte, da ciência e do que quer que seja. No prefácio de 1886 (MA I/HH I 3, KSA 2.15-17), será a questão dos valores, no plural e sem epíteto nem genitivo ${ }^{50}$. Não se trata mais, portanto, do problema do valor da história, mas dos valores na história, estes transformando o próprio homem enquanto agregado de instintos.

\section{II.2. História e utilidade.}

Que a crítica deve ser histórica é, assim, um ponto doravante estabelecido $^{51}$. A verdadeira dificuldade consiste em determinar qual historicidade precisa se deve utilizar, pois há muitas maneiras de derivar um contrário de um contrário... O procedimento experimental de Nietzsche o conduziu, sem dúvida, a considerar várias soluções, simultâneas e não logicamente compatíveis, para uma dificuldade que lhe era imperativamente preciso resolver, sob pena de ver a "filosofia histórica" permanecer uma simples palavra de ordem. Mas é certo que uma saída se lhe apresentou sob a espécie do modelo utilitarista.

Eis um recurso que ele partilha com Rée, que sustentava que "o comportamento não egoísta é objeto de elogios porque é útil"52.

50 Aqui seria preciso estudar escrupulosamente os usos nietzschianos do termo "valor" anteriores a 1878.

51 Por isso, o procedimento de Paul Katsafanas, que se esforça para demonstrar por que Nietzsche, em 1887, recorre à história, parece-nos inutilmente laborioso (The relevance of history for moral philosophy: a study of Nietzsche's Genealogy. In: Nietzsche's On the Genealogy of Morality, § 9; editado por Simon May. Cambridge/Nova York: Cambridge U.P., 2011): a verdadeira questão diz respeito às especificidades da historicidade genealógica.

52 RÉE, P. L'origine des sentiments moraux. Trad. fr. M.-F. Demet. Paris: PUF, 1982, p.90. Além da introdução de P.-L. Assoun à mencionada tradução francesa, pode-se consultar FORNARI, M. La morale evolutiva del gregge. Nietzsche legge Spencer et Mill. Pisa: ETS, 2006; e também SMALL, R. Nietzsche and Rée. A Star Friendschip. Oxford: Oxford UP, 2007.

50 I Cad. Nietzsche, São Paulo, n. 34 - vol. I, p. 35-62, 2014. 
É claro que, assim, ambos se inscrevem na esteira das filosofias do interesse provenientes de La Rochefoucauld que chegam a Darwin por intermédio de toda uma órbita especificamente inglesa. A grande vantagem de tal tradição é permitir pensar uma historicidade ateleológica, precisamente o que procura Nietzsche: livrar-se da influência de Schopenhauer sem divinizar o vir a ser. É por este motivo que se volta para a Inglaterra, para escapar de uma alternativa que, no fundo, lhe impedia de ser filólogo $e$ filósofo, a não ser pela mediação de um falso passado totalmente inventado, o do mito - não é isso que define o impasse wagneriano?

Desses recursos temos testemunhos instrutivos, por exemplo, no $§ 92$ do primeiro volume de Humano, demasiado humano: num primeiro momento, a justiça é reconduzida a uma origem egoísta, o instinto de conservação, evidentemente, que incita os indivíduos com potências aproximadamente iguais a evitarem o conflito e reconhecerem-se mutuamente; mas, num segundo momento, o hábito recobre a utilidade originária e assim se esquece por que se denomina "justo" o que se julga "justo". É preciso então legitimar de outro modo tal designação, e inverte-se o motivo inicial: "pouco a pouco surgiu a aparência de que uma ação justa é uma ação não egoísta" (MA I/HH I 92, KSA 2.90, trad. Rubens Rodrigues Torres Filho) ${ }^{53}$. Dois anos mais tarde, no $\S 40$ de $O$ andarilho e sua sombra, intitulado "A significação do esquecimento no sentimento moral", reencontramos quase a mesma análise: é a utilidade comum [der gemeinsame Nutzen] que comandou a distinção original entre o permitido e o proibido, mas, com o passar do tempo, esqueceu-se a utilidade e julgam-se as mesmas ações morais por outros motivos ${ }^{54}$. Assim,

53 Um pouco adiante (MA I/HH I, 103, KSA 2.100, trad. Paulo César de Souza), Nietzsche reafirmará que a única razão para proibir-se prazeres egoístas é, no início, o "ponto de vista da utilidade [vom Gesichtspunkte des Nutzens]".

54 Se atento, o leitor notará que a segunda parte da argumentação de Nietzsche (desqualifica-se todo interesse para melhor condenar o interesse pessoal) sobrepõe-se notavelmente ao argumento utilizado por Bentham em sua Introdução aos princípios da moral e da legislação, cap.II, § 9: o ascetismo condena todo prazer para melhor rejeitar os prazeres dispendiosos. Ainda se trata de jogar o bebê com a água do banho. 
Binoche, B.

Nietzsche lança mão de um esquema perfeitamente identificável: na origem, a utilidade dita o valor, depois o hábito recobre a causa, deixando subsistir o efeito, ao qual é preciso, por conseguinte, estabelecer, retrospectivamente, uma nova causa, completamente fictícia; é por isso que a história dos sentimentos não pode ser identificada com a dos conceitos que os designam posteriormente. Olhando de perto, a origem não desaparece, ela permanece, mas dissimulada pela segunda origem que se lhe sobrepõe a posteriori: "Tais ações, em que foi esquecido o motivo fundamental, o da utilidade, denominam-se então morais: não porque seriam realizadas por aqueles outros motivos, mas porque não são feitas em nome da utilidade consciente" (WS/AS 40, KSA 2.570, trad. Paulo César de Souza). Se ainda resta a fazer a história de tal esquema, dele, porém, o leitor encontrará um exemplo interessante em Mandeville, na segunda parte de A fábula das abelhas (1729) ${ }^{55}$, em que verá como, o homem social tendo sido constrangido pela educação a ocultar ao outro seu orgulho natural, "é possível que com o tempo ele chegue a se esquecer de seu princípio de partida e que se torne ignorante, ou ao menos inconsciente, da fonte oculta que dá vida e movimento a todas as suas ações" ${ }^{96}$. Notar-se-á que, numa tal perspectiva, o esquecimento encontra-se necessariamente assimilado a uma espécie de erosão natural dos traços, ao seu apagamento gradual pelo hábito, em contradição com a faculdade positiva que levava em conta, contra a memória histórica, o $§ 1$ da segunda Extemporânea (HL/Co. Ext. II 1, KSA 1.248-257). E, finalmente, não causará surpresa que Nietzsche tenha procurado na Inglaterra uma historicidade que lhe permitisse escapar das teleologias alemãs.

55 Antes, portanto, da crítica humiana do contrato social na segunda parte do livro III do Tratado da natureza humana (1740). A aproximação com Mandeville havia sido feita em 1904 por S. Danzig, Drei Genealogien der Moral: Bernard de Mandeville, Paul Rée und Friedrich Nietzsche. Pressburg: A. Alkalay und Sohn.

56 MANDEVILLE. La fable des abeilles, II, segundo diálogo. Trad. fr. L. Carrive. Paris: Vrin, 1991, p.73.

52 I Cad. Nietzsche, São Paulo, n. 34 - vol. I, p. 35-62, 2014. 
Certamente, desde 1881, tal tipo de explicação parece a Nietzsche insatisfatório: o $\$ 37$ de Aurora (KSA 3.44-45) dissocia brutalmente a origem [der Ursprung] da utilidade [die Nützlichkeit] e o $\S 360$ (KSA 3.241) opõe esta [der Nutzen] ao sentimento de potência [das Gefiuhl der Macht]. Reunidas as duas teses, chega-se à formidável análise proposta em 1887 em Para a genealogia da moral (GM/GM II, 12, KSA 5.313-316), em que, a propósito do castigo, encontra-se exposta a historicidade genealógica propriamente dita, segundo a qual toda coisa sempre se encontra já interpretada por uma vontade de potência que lhe confere seu valor e seu sentido até que outra vontade de potência se aposse dela e a recubra com um novo valor e um novo sentido, para além de qualquer "evolução" e em total contingência.

Mas isso não foi tão simples. Se o espaço deste artigo permitisse, poder-se-ia mostrar que o conjunto de $A$ gaia ciência é percorrido por uma surda discussão com o utilitarismo, que Nietzsche não cessa de, simultaneamente, mobilizar e recusar, de tal modo que com frequência parece empreender uma crítica interna ao utilitarismo.

É que a dupla recusa fundamental da metafísica e da democracia atinge a utilidade. Em quê a utilidade pode ser dita "metafísica"? Simplesmente nisto: quando se reduz o bom ou o verdadeiro ao útil e o mau ou o falso ao nocivo, acredita-se ser muito perspicaz, mas evidentemente se continua a pressupor que o bem e o mal ou que o verdadeiro e o falso existam por eles mesmos eternamente ${ }^{57}$, esquecendo-se, porém, que eles são o que são em virtude de seu caráter útil ou, ao contrário, danoso (FW/GC 4 e 110, KSA 3.376377 e 469-471): a substituição da razão suficiente original pelo hábito não muda absolutamente nada na própria distinção entre

57 Cf. Bentham, op. cit., cap. X, § ii, 10, p.129: "Ora, o prazer é em si mesmo um bem, e mesmo, excetuando-se a imunidade da dor, o único bem. A dor é em si mesma um mal; e, em verdade, sem exceção, o único mal; de outro modo, as palavras bem e mal não têm sentido algum". 
Binoche, B.

o bem e o mal ou entre o verdadeiro e o falso, continuando-se a hipostasiar ingenuamente os contrários nas antinomias que precisamente definem a metafísica ${ }^{58}$. E declinando-se a utilidade num modo evolucionista, do progresso em vez do esquecimento, chegar-se-á exatamente à mesma conclusão: "Útil-nocivo" 'Utilitário" Semelhante palavrório tem por base o preconceito de que se sabe em que direção o ser humano (ou ainda o animal, a planta) deve [solle] evoluir"59.

Além disso, a pretensa utilidade é utilidade para o rebanho: toda moral comunitária deve sua existência à sua utilidade... para a comunidade (FW/GC 116, KSA 3.474-475), e, se as virtudes de um indivíduo são qualificadas como "boas", é porque elas o são "para nós e a sociedade", mas não para o próprio indivíduo concernido (FW/GC 21, KSA 3.391, trad. Paulo César de Souza). Por isso, a utilidade, enquanto valor, deve ser referida ao vulgar, em oposição ao nobre, que a contrario age de outra maneira que não em virtude dos cálculos de interesse (FW/GC 3, KSA 3.374-376) que se pense nos decretos de honra, que parecem completamente ridículos ao burguês. Também nesse caso, que nos refiramos à comunidade original ou à espécie em progresso, ainda temos de nos haver com a massa.

Mas uma análise apurada mostraria sem dificuldade que tais críticas permanecem envoltas numa apreciação ambivalente do utilitarismo. Por exemplo, a moral comunitária só é útil ao rebanho, mas, afinal, é esse instinto gregário que determina a moral, é ele que tem a primeira palavra, se não a última (FW/GC 116, KSA 3.474-475), e, se é preciso opor os valores vulgares aos valores nobres, é sob a forma mesma de uma antinomia, e não de uma sucessão (FW/GC 3, KSA 3.374-376). Ainda por exemplo, é falso que por natureza a verdade seja útil à espécie e que o falso lhe seja nocivo;

58 Nachlass/FP 1881, 11[106], KSA 9.479, trad. modificada.

59 Nachlass/FP 1881, 11[106], KSA 9.479, trad. modificada.

54 I Cad. Nietzsche, São Paulo, n. 34 - vol. I, p. 35-62, 2014. 
é que as grandes teses metafísicas (crença em livre arbítrio, essência etc.) são de fato erros úteis à espécie (FW/GC 110, KSA 3.469-471). Em certos casos, Nietzsche continua a recorrer ao esquema do esquecimento, por exemplo, quando se trata de evocar a querela do Cid e as três unidades de Aristóteles, para as quais se inventaram justificações retrospectivas para não se reconhecer que apenas o hábito, desde muito tempo, tornava-as dominantes (FW/GC 29, KSA 3.401). Em outra parte, é a própria poesia que deve sua origem à superstição em virtude da qual se pensava constranger os deuses, pelo ritmo do verbo, a favorecerem nossos interesses, e a afirmação moderna de um juízo estético por natureza desinteressado só se pode explicar pelo esquecimento de tal crença (FW/GC 84, KSA 3.439-442, trad. Paulo César de Souza). Mas, nesse segundo caso, a reticência de Nietzsche em mobilizar tal explicação se exprime duplamente: por um lado, ao sublinhar o caráter fantasmático da utilidade originária - "sem dúvida, uma utilidade supersticiosa!"; por outro, ao indicar o caráter excepcional de semelhante recurso: "Bem, neste caso tenho que falar em favor dos utilitaristas" - como se adotasse a análise por falta de outra... Em outra parte ainda, o politeísmo se explica por sua "utilidade maior [größter Nutzen]", que consistiu, muito teleologicamente, em valorizar a individualidade sob a forma dos deuses, isto é, uma pluralidade de normas, que agora temos de fazer descer à terra. Parece que Nietzsche, nesse ponto de sua trajetória, efetivamente não pode abrir mão de um modo de análise que lhe permite dar corpo a sua "filosofia histórica", mas do qual, ao mesmo tempo, procura desembaraçar-se, voltando-o contra si próprio pelo viés de diversas estratégias irredutíveis umas às outras.

III. A genealogia

III.1. Filologia

Cad. Nietzsche, São Paulo, n. 34 - vol. I, p. 35-62, 2014. 
Binoche, B.

Talvez não se note suficientemente que, inscrevendo o termo "genealogia" na página de título da obra de 1887, Nietzsche empregava um novo significante para designar sua história dos sentimentos morais. Trata-se de um termo raro na tradição filosófica, mas é bastante notável que Mandeville, em quem encontramos acima um exemplo, se não talvez a primeira ocorrência, do esquema do esquecimento e da falsificação retrospectiva dos motivos individuais, recorre a ele precisamente para definir a contrario seu procedimento na esteira de La Rochefoucauld: "A tarefa de sua filosofia é justamente o contrário da tarefa da repartição de brasões; pois aí se trabalha sem cessar para descobrir sem cessar elevadas e ilustres genealogias para pessoas baixas e obscuras, e vosso autor está sempre a procurar e a inventar origens vis e desprezíveis para ações dignas e honoráveis" ${ }^{\circ}$. Tampouco é sem interesse notar que Rousseau o utiliza duas vezes para designar sua genealogia da desigualdade e dos afetos correspondentes ${ }^{61}$ - Rousseau, que sempre permaneceu uma bête noire para Nietzsche, mesmo que este lhe seja, por vezes, bem mais próximo do que tem consciência ${ }^{62}$. Dito isso, a história da metáfora genealógica ainda está por ser feita.

No próprio Nietzsche, parece, só encontramos muito raramente ocorrências de tal termo antes de $1887^{63}$. A primeira delas remonta a $O$ drama musical grego, conferência pronunciada em 18 de janeiro de 1870, em cuja primeira página se aprende que o drama shakespeariano atesta um "parentesco genealógico [eine genealogische Verwandtschaft]" incontestável com a nova comédia ática ${ }^{64}$. A segunda se encontra num fragmento póstumo da primavera de 1871-início de 1872 que diz: "O sacerdote como filósofo: a genea-

60 Primeiro diálogo, op. cit., p.34 (ver também p.60, 73, 238, 248 e 251).

61 Euvres complètes. Paris, Gallimard, 1959-1995: tomo III, p.49, e tomo IV, p.936.

62 Notadamente no $§ 2$ de Humano, demasiado humano (KSA 2.24-25), que evoca irresistivelmente o argumento central do segundo Discours de Rousseau: os filósofos projetaram o homem tal como se tornou na origem.

63 Sob reserva de verificação.

64 GMD/DM, KSA 1.515-516.

56 I Cad. Nietzsche, São Paulo, n. 34 - vol. I, p. 35-62, 2014. 
logia [die Genealogie], os diferentes pensadores do mundo, Delfos como regulador. A sabedoria dos mistérios" ${ }^{" 65}$ - e inevitavelmente se pensa na derivação do filósofo a partir do sacerdote que de fato Nietzsche operará em $1887^{66}$. A terceira ocorrência figura num fragmento póstumo de 1884 que menciona: "Todos os falsos 'contrários' (a propósito da transformação [Verwandlung] dos afetos, de sua genealogia [ihre Genealogie] etc." ${ }^{97}$ - e imediatamente se pensa no que, em 1878, era designado sob o nome de "filosofia histórica". Enfim, numa quarta ocorrência do mesmo ano, Nietzsche evoca sua própria "genealogia filosófica [philosophische Genealogie]" e a vincula ao movimento "antiteleológico, isto é, espinosista, de nossa época" ${ }^{\circ 8}$. Esses textos nos permitem constatar:

- primo, que o termo genealogia sempre se remeteu, sem dúvida, à mesma preocupação, a saber, com uma historicidade original que supera as alternativas com as quais Nietzsche é confrontado;

- secundo, que ele se impõe frequentemente por associação com o parentesco e as metamorfoses (Verwandtschaft, Verwandlung) da mitologia ${ }^{69}:$ não é mais na fabulação mítica que se deve procurar a mediação entre filosofia e história, mas na narrativa genealógica que reivindica o cinza do arquivo, a qual se apresentará notadamente sob a forma da etimologia;

- tertio, que toda genealogia se concebe, sem dúvida, contra outra genealogia - a de Nietzsche não é a de Hartmann;

- quarto, e trata-se do essencial, que o termo permanece acidental até 1887, quando surge na dianteira da cena precisamente para dizer que a "filosofia histórica" não é satisfatória enquanto permanece tributária ao esquema utilitarista.

65 Nachlass/FP 1871-1872, 14[27], KSA 7.386.

66 GM/GM III, 10, KSA 5.359-361.

67 Nachlass/FP 1884, 26[391], KSA 11.253.

68 Nachlass/FP 1884, 26[432], KSA 11.266.

69 O fragmento de 71-72 menciona exatamente antes da citação acima: "O poeta como filósofo. Sabedoria arcaica em sentenças. Hesíodo Teógnis Focílides". 
Binoche, B.

\section{2. Genealogia versus utilitarismo}

Com efeito, não é de modo algum por acaso se Para a genealogia da moral replica discussões com Rée e sem tardar rejeita explicitamente, e com insistência, o procedimento empregado por este. $\mathrm{O}$ prefácio combate em duas frentes: por um lado, a da própria moral, o niilismo de que Schopenhauer e sua apologia da compaixão são a expressão mais sintomática; por outro lado, a do método a se empregar para historicizar a moral, o utilitarismo inglês, ao qual Rée é abruptamente remetido: ele também considera a avaliação altruísta "como o modo de valorar em si" (GM/GM Prefácio 4, KSA 5.251, trad. Paulo César de Souza), isto é, como tendo sido sempre reconhecido pelo homem como exclusivo. A primeira dissertação retoma essa crítica e a desenvolve. Nietzsche começa por lembrar (GM/GM I, 1, KSA 5.257-258) que uma tal abordagem tem o mérito de efetuar uma espécie de "genealogia", uma vez que deriva o contrário nobre do contrário vil. Mas imediatamente ele mostra por que uma tal história decididamente não o é de fato, e é este argumento que importa aqui (GM/GM I, 2, KSA 5.258-260). A descrição feita do esquema utilitarista corresponde ponto a ponto não somente àquela de Rée., mas também àquela que empregava o próprio Nietzsche: a origem, depois o esquecimento da origem recoberta pelo hábito, enfim a reinterpretação falaciosa da origem. Toda análise desse gênero, diz-se agora, procede de um duplo contrassenso. $\mathrm{O}$ primeiro consiste em presumir que a própria distinção entre o bem e o mal nunca mudou - transformaram-se apenas as razões que se dá reflexivamente para observá-la. $O$ segundo consiste em prejulgar que são os beneficiários de tal distinção, id est, a massa, que a decidiram, em função do que lhes era útil ${ }^{70}$. Eis por que, finalmente, em semelhante história dos valores, os valores não têm história: nem a antinomia muda (o bem e o mal), nem o critério da antinomia (a utilidade),

70 Aqui não é sem interesse notar que Bentham, com efeito, dizia que a multidão era "o manufaturador da linguagem [the manufacturers of language]" (op. cit., cap. X, § 23, p.137).

58 I Cad. Nietzsche, São Paulo, n. 34 - vol. I, p. 35-62, 2014. 
nem aquele que a institui (o rebanho). A contrario, deve-se dizer que a distribuição diz respeito a uma aristocracia à qual cabe decidir e que decide não em função da utilidade vulgar, mas em referência a algo como a honra feudal; deve-se acrescentar que uma real inversão de valores se efetuará quando os oprimidos chegarem a impor sua distinção e o critério correlativo; e disso se deve induzir que a genealogia utilitarista é ela mesma uma falsificação, contra a qual se trata de promover uma outra genealogia, realmente histórica - é também por isso que a obra é subtitulada "um escrito polêmico". Ao mesmo tempo, enfim, o esquecimento, no início da segunda Abhandlung, tornar-se-á novamente o que era em 1874, i.e., uma potência de ocultação necessária à vida, e não a simples deterioração dos traços no decorrer do tempo.

Impõe-se a conclusão: a crítica só é tão violenta porque é uma autocrítica, da qual procede a "genealogia" propriamente dita" . Após ter recorrido ao utilitarismo para dar corpo a uma história dos sentimentos morais despojada de toda teleologia, Nietzsche se desembaraça do próprio utilitarismo, sob sua forma clássica como sob sua forma biológica, para instituir uma historicidade completamente original. Esta requer um nome, até então permanecido às margens da terminologia filosófica, que consuma metodologicamente a morte de Deus: a saber, a sucessão contingente de hegemonias sempre provisórias e mais ou menos suscetíveis de se exercerem sem má consciência ${ }^{72}$.

Portanto, afinal de contas, não é nem o que é originalmente favorável à comunidade nem o que é teleologicamente favorável à espécie que autoriza a genealogia dos valores. É, se se quiser, o que é "útil" às vontades de potência, isto é, aos modos de existência,

71 É o ponto que me parecem deixar escapar STEGMAIER, W. Nietzsches "Genealogie der Moral". Darmstadt: Wissenschaftliche Buchgesellschaft, 1994, p.94-103 e PORCHER, F. Sens et portée de l'anti-utilitarisme de Nietzsche. In: Revue du MAUSS, 35, 2010/1, p.365379, a despeito da grande perspicácia deles. Ambos partem da crítica formulada em 1887, em vez de se perguntarem como Nietzsche chega a ela.

72 GM/GM II, 12, KSA 5.313-316. 
Binoche, B.

aos tipos que se impõem aleatoriamente e que não podem avaliar o mundo circunvizinho e se avaliar a si próprios de outra maneira senão em função do que lhes permite precisamente estender sua potência. Tal é o útil genealógico, correlativo de uma historicidade inédita e emancipado do simples instinto de conservação assim como de todo hedonismo simplório, enfeudado, em compensação, à potência, isto é, à propagação dos valores idiossincrásicos. Nietzsche in fine ainda utilitarista, mas de outra maneira.

\begin{abstract}
The question which Nietzsche asks in 1874 is the one of the value of history; it can be asked only because it refers history to something external, life, qualified as unhistorical. In 1878, Nietzsche reverses his interrogation and he asserts the identification of the life to the history, opening in this way the possibility of an history of values. The problem becomes how to take shape this one. Nietzsche uses then the utilitarist outline, with which he starts a long debate, as The Gay Science shows it right in 1882. In 1887, the concept of "genealogy" is promoted to signify a new historicity, the possibility of which is in the liquidation of this outline, so that the critic of Paul Rée must be understood as a self-critic.
\end{abstract} Keywords: history - value - genealogy - utilitarism

\title{
referências bibliográficas
}

1. ARISTÓTELES. Métaphysique. Trad. M.-P. Duminil e A. Jaulin. Paris: GarnierFlammarion, 2008.

2. BENTHAM, J. Introduction aux principes de morale et de législation. Trad. Centre Bentham. Paris: Vrin, 2011.

3. BUCKLE, H.T. History of Civilization in England. London: John W. Parker, 1857-1861.

4. BURCKHARDT, J. Considérations sur l'histoire universelle. Trad. fr. S. StellingMichaud. Paris: Payot, 1965.

5. DANZIG, S. Drei Genealogien der Moral: Bernard de Mandeville, Paul Rée und Friedrich Nietzsche. Pressburg: A. Alkalay und Sohn, 1904.

60 I Cad. Nietzsche, São Paulo, n. 34 - vol. I, p. 35-62, 2014. 
6. DELEUZE, G. Nietzsche et la philosophie. Paris: PUF, 1962.

7. D'IORIO, P. Le voyage de Nietzsche à Sorrente. Paris: CNRS Editions, 2012.

8. DROYSEN, J.G. Précis de théorie de l'histoire. Trad. A. Escudier. Paris: Cerf, 2002.

9. FORNARI, M. La morale evolutiva del gregge. Nietzsche legge Spencer et Mill. Pisa: ETS, 2006.

10. HARTMANN, E. von. Le panthélisme de Schopenhauer. Trad. fr. V. Stanek. Les Etudes Philosophiques, n³/2012, p.409-419.

11. HEGEL, G.W.F. Principes de la philosophie du droit. Trad. R. Derathé/J.P. Frick. Paris: Vrin, 1982.

12. .La philosophie de l'histoire. Trad. M. Bienenstock et al. Paris: Librairie générale française, 2009.

13. JANZ, C.P. Nietzsche. Biographie. Trad. P. Rusch. Paris: Gallimard, 3 volumes, 1984.

14. JENSEN, A.K. Nietzsche's Philosophy of History. Cambridge/New-York: Cambridge U.P., 2013.

15. KANT, E. Idée d'une histoire universelle du point de vue cosmopolitique. In: Opuscules sur l'histoire. Trad. S. Piobetta. Paris: Garnier-Flammarion, 1990.

16. KATSAFANAS, P. The relevance of history for moral philosophy: a study of Nietzsche's Genealogy. In: Nietzsche's On the Genealogy of Morality, editado por Simon May. Cambridge/New-York: Cambridge U.P., 2011, p.170-192.

17. LA ROCHEFOUCAULD, F. de. Réflexions ou Sentences et Maximes morales. In: Moralistes du XVIIe siècle, ed. Jean Lafond. Paris: Robert Laffont, 1992.

18. LE RIDER, J. La vie, l'histoire et la mémoire dans la seconde Considération inactuelle de Nietzsche. In: Littérature et nation, 1999, n. 21, p.159-186.

19. MANDEVILLE, B. La fable des abeilles, seconde partie. Trad. fr. L. Carrive. Paris: Vrin, 1991.

20. MARX, K. L'idéologie allemande. Trad. M. Rubel. In: Euvres. Paris: Gallimard, tomo III, 1982.

21. MÜLLER-LAUTER, W. Nietzsche. Physiologie de la volonté de puissance. Trad. J. Champeaux. Paris: Allia, 1998.

22. NIETZSCHE, F. Sämtliche Werke. Kritische Studienausgabe in 15 Bänden. Organizada por Giorgio Colli e Mazzino Montinari. München: Walter de Gruyter, 1999.

23. __ Euvres philosophiques complètes. Ed. Giorgio Colli e Mazzino Montinari. Trad. francesa. Paris: Gallimard, 1968-1997, 18 volumes.

24. Friedrich Nietzsche. Obras incompletas. Trad. Rubens Rodrigues Torres Filho. Col. "Os pensadores”. São Paulo: Abril Cultural, 1974.

25. A gaia ciência. Trad. Paulo César de Souza. São Paulo: Companhia das Letras, 2001. 
Binoche, B.

26. ___ém do bem e do mal: prelúdio a uma filosofia do futuro. Trad. Paulo César de Souza. São Paulo: Companhia das Letras, 1992.

27. Assim falou Zaratustra: um livro para todos e para ninguém. Trad. Paulo César de Souza. São Paulo: Companhia das Letras, 2011.

28. __ Genealogia da Moral: uma polêmica. Trad. Paulo César de Souza. São Paulo: Companhia das Letras, 1998.

29. Humano, demasiado humano: um livro para espíritos livres. Trad. Paulo César de Souza. São Paulo: Companhia das Letras, 2000.

30. Humano, demasiado humano: um livro para espíritos livres volume II. $\mathrm{O}$ andarilho e sua sombra. Trad. Paulo César de Souza. São Paulo: Companhia das Letras, 2008.

31. PORCHER, F. Sens et portée de l'anti-utilitarisme de Nietzsche. In: Revue du MAUSS, $35,2010 / 1$, p.365-379.

32. RÉE, P. L'origine des sentiments moraux. Trad. M.-F. Demet. Paris: PUF, 1982.

33. ROUSSEAU, J.-J. Euvres complètes. Paris, Gallimard, 1959-1995, 5 volumes.

34. SALAQUARDA, J. Studien zur zweiten unzeitgemäßen Betrachtungen. In: NietzscheStudien, n.13, 1984, p.1-45.

35. SCHILLER, F. Was heisst und zu welchem Ende studiert man Universalgeschichte? In: Werke, Nationalausgabe, herausgegeben von Ernst Behler. Weimar: H. Böhlhaus, 1970, t.XVII, p.359-376.

36. SCHOPENHAUER, A. Le monde comme volonté et représentation. Trad. A. Burdeau. Paris: PUF, 1978.

37. SMALL, R. Nietzsche and Rée. A Star Friendschip. Oxford: Oxford UP, 2007.

38. SMITH, A. Théorie des sentiments moraux. Trad. M. Biziou, C. Gautier e J.-F. Pradeau. Paris: PUF, 1999.

39. STEGMAIER, W. Nietzsches “Genealogie der Moral”. Darmstadt: Wissenschaftliche Buchgesellschaft, 1994.

40. TOCQUEVILLE, A. de. De la démocratie en Amérique. In Euvres, ed. André Jardin, tomo II. Paris: Gallimard, 1992.

41. TOLSTOI, A. Guerre et paix. Trad. H. Mongault. Paris: Gallimard, 1952.

Artigo recebido para publicação em 15/04/2013.

Artigo aceito para publicação em 20/05/2013.

62 I Cad. Nietzsche, São Paulo, n. 34 - vol. I, p. 35-62, 2014. 